\title{
Identidad e imagen corporativas: revisión conceptual e interrelación
}

DOI: 10.22403/UQROOMX/TYP07/01

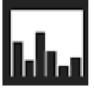

Rafael Currás Pérez

Universitat de València

\section{Resumen}

Este artículo tiene dos objetivos generales: primero, revisar teóricamente las nociones de identidad e imagen corporativas, destacando sus diferencias y exponiendo las inconsistencias conceptuales que existen en la literatura académica sobre marketing corporativo; segundo, examinar la interrelación entre ambos, con énfasis en el papel de la cultura organizacional como contexto simbólico en el que se produce esa interdependencia. Para la consecución de estos objetivos, se diseñó una investigación cualitativa de naturaleza conceptual, basada en una extensa revisión de la literatura académica en management y marketing sobre las nociones básicas de identidad e imagen corporativas. En este trabajo se ofrece tal revisión, y se presentan conclusiones de interés para académicos y profesionales, así como posibles líneas de investigación futura.

Palabras | Cultura organizacional, identidad corporativa, imagen corpora-

CLAVE tiva, marketing corporativo, revisión de la literatura. 
Identidad e imagen corporativas:

revisión conceptual e interrelación

\section{Introducción}

Hoy en día, la gestión de la imagen de la empresa ha adquirido una relevancia enorme para las corporaciones modernas, lo que la convierte en un instrumento de diferenciación y obtención de ventajas competitivas (Balmer, 2008; Melewar y Karaosmanoglu, 2006). Las actuales dinámicas del mercado invitan a las empresas a cuidar sobremanera los atributos y características organizacionales y de la marca, por cuanto son más duraderos y resistentes a las presiones competitivas que los atributos propios de servicio/producto, más fáciles de copiar (Bhattacharya y Sen, 2003; Aaker, 2004). En entornos crecientemente complejos, dinámicos y cambiantes, las decisiones basadas en conocimientos referidos a simples imágenes (aunque sean conocimientos parciales, exiguos o poco contrastados) son cada vez más comunes (van Riel, 1995). Gracias a que las imágenes dotan de significado y posibilitan el conocimiento y aprendizaje de una realidad (la empresa, la marca), cumplen para el sujeto (por ejemplo, consumidor o inversionista) una función de simplificación de los procesos de obtención de información y búsqueda de oferta, que les facilita sus decisiones de consumo (Poiesz, 1988).

Así, no es raro que en los últimos años se haya generado una nueva área de estudio: el marketing corporativo, fruto del importante desarrollo de la investigación académica en torno a conceptos interrelacionados como identidad, imagen, personalidad, branding o comunicación, referidos a la organización en su totalidad, a la empresa en su conjunto (Balmer, 2008). Sin embargo, pocos campos de estudio han sido objeto de tanta oscuridad e imprecisión conceptual como el relativo a la identidad e imagen corporativas (Alessandri, 200I; Balmer, 200I; Melewar y Karaosmanoglu, 2006). Según Balmer (200I), este campo de estudio ha vivido en una auténtica niebla conceptual, cuya principal causa es la ambigüedad en la terminología utilizada en la academia. La ubicuidad de las denominaciones, empleadas con mucha permisividad en distintos contextos, relacionadas con diversas áreas de estudio y tratadas de forma diferente por la literatura académica y la de gestión, ha generado un conjunto de conceptos interrelacionados, mal delimitados y definidos sobre los que conviene realizar un esfuerzo adicional de revisión y clarificación (Cornelissen y Elving, 2003; Otubanjo y Melewar, 2007).

Una de las cuestiones que más ha preocupado a los investigadores es conocer qué relación se establece entre los dos principales elementos del marketing corporativo: identidad e imagen corporativas. La relación tradicional que 
se ha dado entre ambos se basa en el modelo comunicativo clásico emisorreceptor, en donde la imagen es dependiente de la identidad (Christensen y Askegaard, 200I; Dowling, 1986; Margulies, 1977). Entonces, la identidad corporativa se ha concebido como algo interno y controlable por la organización, que se proyecta de modos concretos con el objetivo de generar una impresión (imagen) específica en los diversos stakeholders (por ejemplo trabajadores, consumidores o inversionistas) con los que se relaciona la empresa.

No obstante, esta relación de dependencia de la imagen respecto a la identidad corporativa ha sido puesta en duda por varios autores (Abratt, 1989; Dutton y Dukerich, 1991; Stuart, 1999), que consideran que entre ambos elementos existe una relación de interdependencia, ya que la imagen corporativa también influye en lo que la organización es o pretende ser. Ahora bien, esta naturaleza dialógica de la relación identidad-imagen no ha sido del todo internalizada por los mánagers, que únicamente se preocupan por la gestión de la imagen externa de la empresa -dados los beneficios que en sí misma reporta-, sin atender a su posible influencia sobre la identidad de la organización.

Debido a estas cuestiones, es útil y necesario, tanto para la investigación académica posterior como para los gestores, un esfuerzo de clarificación conceptual de las nociones de identidad e imagen corporativas, así como un examen de su interrelación, de manera que se permita el desarrollo de estrategias eficaces de gestión de ambos conceptos. Con este enfoque, el presente trabajo se propone dos objetivos principales: I) revisar teóricamente las nociones de identidad e imagen corporativas, destacando sus diferencias y exponiendo las inconsistencias conceptuales que existen en la literatura;y 2) examinar la interrelación entre esos dos elementos, haciendo hincapié en el papel de la cultura organizacional como contexto simbólico en el que se produce esa interdependencia.

Para la consecución de dichos objetivos, se diseñó una investigación cualitativa de naturaleza conceptual fundada en una extensa revisión de la literatura académica en management y marketing sobre las nociones básicas de identidad e imagen corporativas. En el primer apartado del artículo se revisa, desde un punto de vista teórico, el concepto de identidad corporativa, poniendo el énfasis en la clarificación de la ambigüedad esencial que existe en torno al concepto en la literatura académica en marketing y comportamiento organizacional, utilizando para ello el marco conceptual del proceso de significación de Peirce (1985), con base en el trabajo de Christensen yAskegaard (200I). A continuación, 
Identidad e imagen corporativas:

revisión conceptual e interrelación

se presenta el conjunto de conceptualizaciones aparecido en torno al término imagen, con especial atención en la delimitación de la imagen corporativa y sus diferencias con la identidad. En el siguiente apartado se examina la relación interdependiente entre la identidad y la imagen corporativas, gracias al papel desempeñado por la cultura organizacional (Hatch y Schultz, 1997 y 2002). Y, por último, una vez completada esta revisión y clarificación conceptual, se ofrecen las principales conclusiones y limitaciones del trabajo, así como las líneas de investigación futura que de él se derivan.

\section{Revisión conceptual de la identidad corporativa}

Si hay algo que caracteriza a la noción de identidad, en sus múltiples facetas, es su ubicuidad: el término ha sido utilizado con mucha permisividad en diferentes contextos, investigado tanto por literatura académica como práctica y atribuido y relacionado con diversos campos de estudio (Balmer, 200 I; Hatch y Schultz, 1997). Alrededor de la noción de identidad han aparecido un conjunto de conceptos interrelacionados -en innumerables ocasiones mal delimitados y definidos-, como identidad corporativa, identidad de marca, identidad organizacional, identidad visual o identidad de negocio. Balmer (200I), en su intento integrador, emplea la identidad de negocio como un término paraguas que incluye tres conceptos relacionados, pero diferentes: identidad visual, identidad organizacional e identidad corporativa.

La identidad visual hace referencia a la representación gráfica de la identidad corporativa, en forma de símbolos y señales como marcas, logotipos, decoración, estilo corporativo, vestuario del personal, etc. (Chajet y Shachtman, 1998; van Riel, 1995). En cuanto a la identidad organizacional (término más usado en el área de comportamiento organizacional) existe un elevado consenso sobre su conceptualización, gracias a la influyente definición seminal propuesta por Albert y Whetten (1985) como aquello que los miembros perciben como lo central, distintivo y duradero en la organización. Es decir, el término es utilizado para designar aquello que los miembros formales de la organización piensan y sienten respecto a ella, lo que se deriva de su percepción individual de los atributos centrales, distintivos y duraderos que la caracterizan (Dutton y Dukerich, 1991; Mael y Ashforth, 1992; Dutton, Dukerich y Harquail, 1994).

Por último, la noción más empleada en el área de marketing, y quizás la que sufre mayor ambigüedad (Christensen yAskegaard, 200 I), es la de identidad 
corporativa. En este apartado se revisa y delimita el concepto. El cuadro I recoge algunas definiciones del concepto identidad corporativa que aparecen en la literatura.

CUADRO I. DEFINICIONES DE IDENTIDAD CORPORATIVA

\begin{tabular}{|c|c|}
\hline Autor(es) & Definición \\
\hline $\begin{array}{l}\text { Margulies } \\
\text { (1977) }\end{array}$ & $\begin{array}{l}\text { Identidad corporativa son todos los mecanismos que una } \\
\text { empresa elige para identificarse ante sus stakeholders -la } \\
\text { comunidad, clientes, trabajadores, medios... }\end{array}$ \\
\hline $\begin{array}{l}\text { Reitter } \\
\text { y Ramanantsoa } \\
(1985)\end{array}$ & $\begin{array}{l}\text { Identidad corporativa es un conjunto de características } \\
\text { interdependientes de una organización, que le dan especificidad, } \\
\text { estabilidad y coherencia y así la hacen identificable. }\end{array}$ \\
\hline $\begin{array}{l}\text { Abratt } \\
(1989)\end{array}$ & $\begin{array}{l}\text { Lo que una audiencia puede reconocer de una empresa y } \\
\text { distinguirla de las otras, y que puede ser utilizado para } \\
\text { representar o simbolizar a la compañía. }\end{array}$ \\
\hline $\begin{array}{l}\text { Olins } \\
\text { (1991) }\end{array}$ & $\begin{array}{l}\text { Consiste en la gestión explícita de algunos o todos los modos } \\
\text { en que las actividades de la empresa son percibidas. Puede } \\
\text { proyectar tres cosas: quién eres, qué haces y cómo lo haces. }\end{array}$ \\
\hline $\begin{array}{l}\text { Van Riel } \\
\text { (1995) }\end{array}$ & $\begin{array}{l}\text { Identidad corporativa es la propia presentación planificada } \\
\text { de la empresa, que se realiza a través de su } \\
\text { comportamiento, comunicación y simbolismo. }\end{array}$ \\
\hline $\begin{array}{l}\text { Van Riel } \\
\text { y Balmer } \\
\text { (1997) }\end{array}$ & $\begin{array}{l}\text { La identidad corporativa indica el modo en que una empresa } \\
\text { se presenta a sí misma a través del comportamiento y el } \\
\text { simbolismo a las audiencias internas y externas. Está } \\
\text { arraigada en el comportamiento individual de los miembros } \\
\text { de la empresa, expresando la uniformidad, distinción } \\
\text { y centralidad de la compañía a lo largo del tiempo. }\end{array}$ \\
\hline $\begin{array}{l}\text { Leuthesser } \\
\text { y Kholi } \\
(1997)\end{array}$ & $\begin{array}{l}\text { Identidad corporativa son los modos en que una } \\
\text { organización revela su filosofía y estrategia a través de la } \\
\text { comunicación, el comportamiento y el simbolismo. }\end{array}$ \\
\hline $\begin{array}{l}\text { Van Rekom } \\
\text { (1997) }\end{array}$ & $\begin{array}{l}\text { La identidad corporativa incluye los elementos } \\
\text { considerados la esencia de la compañía y aquellos que la } \\
\text { diferencian de otras organizaciones a lo largo del tiempo. }\end{array}$ \\
\hline $\begin{array}{l}\text { Markwick } \\
\text { y Fill } \\
\text { (1997) }\end{array}$ & $\begin{array}{l}\text { La presentación de la empresa ante sus stakeholders y los } \\
\text { mecanismos en que se distingue de otras compañías a } \\
\text { través de una variedad de indicadores. Representa cómo le }\end{array}$ \\
\hline
\end{tabular}


Identidad e imagen corporativas:

revisión conceptual e interrelación

CUADRO I. DEFINICIONES DE IDENTIDAD CORPORATIVA

\begin{tabular}{|c|c|}
\hline Autor(es) & Definición \\
\hline & $\begin{array}{l}\text { gustaría a la organización ser percibida y puede incluir } \\
\text { programas de identidad corporativa, publicidad, códigos y } \\
\text { estándares para el trato al cliente. Algunos indicadores } \\
\text { formarán parte de la identidad visual. Otros, se centrarán } \\
\text { en el comportamiento. }\end{array}$ \\
\hline $\begin{array}{l}\text { Moingeon } \\
\text { y Ramanantsoa } \\
(1997)\end{array}$ & $\begin{array}{l}\text { La identidad es un sistema de características que tiene un } \\
\text { patrón y ofrece a la compañía su especificidad, estabilidad } \\
\text { y coherencia. }\end{array}$ \\
\hline $\begin{array}{l}\text { Gray y Balmer } \\
(1998)\end{array}$ & $\begin{array}{l}\text { Identidad corporativa es la realidad y unicidad de una } \\
\text { organización. }\end{array}$ \\
\hline $\begin{array}{l}\text { Hawn } \\
\text { (1998) }\end{array}$ & $\begin{array}{l}\text { Identidad es lo que la empresa es. Imagen es cómo } \\
\text { es percibida. Identidad corporativa es la fusión visual } \\
\text { de la identidad y la imagen. }\end{array}$ \\
\hline $\begin{array}{l}\text { Balmer } \\
\text { y Soenen } \\
(1999)\end{array}$ & $\begin{array}{l}\text { La identidad corporativa comprende tres dimensiones } \\
\text { esenciales: la mente, el alma y la voz. La mente es el producto } \\
\text { de las decisiones conscientes. El alma corresponde a los } \\
\text { elementos subjetivos centrales en la organización, como } \\
\text { los valores corporativos y las subculturas existentes } \\
\text { en ella. La voz representa todos los modos en que } \\
\text { la organización comunica. }\end{array}$ \\
\hline $\begin{array}{l}\text { Gioia, Schultz } \\
\text { y Corley } \\
(2000)\end{array}$ & $\begin{array}{l}\text { La identidad corporativa son las representaciones } \\
\text { consistentes de la compañía con un énfasis en los } \\
\text { símbolos corporativos y logos. Es estratégica y se aplica } \\
\text { tanto interna como externamente. }\end{array}$ \\
\hline $\begin{array}{l}\text { Christensen y } \\
\text { Askegaard (200I) }\end{array}$ & $\begin{array}{l}\text { Identidad corporativa es la suma total de señales que } \\
\text { representan a una organización a sus varias audiencias. }\end{array}$ \\
\hline $\begin{array}{l}\text { Balmer } \\
(2001)\end{array}$ & $\begin{array}{l}\text { La identidad corporativa es la suma de los elementos } \\
\text { tangibles e intangibles que distinguen a una organización, y } \\
\text { está configurada por las acciones de los líderes, por la } \\
\text { tradición y el entorno de la empresa. [...] Tiene un } \\
\text { horizonte multidisciplinar y fusiona la estrategia, estructura, } \\
\text { comunicación y cultura de la empresa. Se manifiesta a través } \\
\text { de múltiples canales, como el comportamiento y la } \\
\text { comunicación de los trabajadores, las herramientas } \\
\text { de comunicación comercial o el desempeño organizacional. }\end{array}$ \\
\hline
\end{tabular}


Como se puede apreciar tras la lectura de las definiciones, existe cierta imprecisión en torno al concepto de identidad corporativa. De forma general, se pueden reconocer dos tipos de conceptualizaciones:

I. las que conciben la identidad corporativa en términos de los modos ("comunicación", "comportamiento", "simbolismo") en que la empresa se representa o proyecta a sí misma (Abratt, 1989; Christensen y Askegaard, 200 I; Gioia, Schultz y Corley, 2000; Leuthesser y Kholi, 1997; Margulies, 1977; Markwick y Fill, 1997; Olins, I99I; van Riel, 1995; van Riel y Balmer, 1997); y

2. aquellas que, además de incluir los modos en que la empresa se representa, dan mayor importancia a un conjunto de elementos esenciales, centrales o fundamentales ("valores","subculturas","alma"), que tienen que ver con lo que objetivamente es la empresa, que la distinguen de otras organizaciones y le confieren individualidad (Balmer, 200I; Balmer y Soenen, 1999; Gray y Balmer, 1998; Hawn, 1998; Moingeon y Ramanantsoa, 1997; Reitter y Ramanantsoa, 1985; van Rekom, 1997).

Así, algunas conceptualizaciones consideran la identidad corporativa como el ethos de la empresa, y cómo éste se representa y manifiesta; mientras que otras se ciñen exclusivamente a los modos que tiene la organización de representarse a sí misma.

Cornelissen y Elving (2003) apuntan que esta doble interpretación de la noción de identidad corporativa está vinculada con el área de estudio en que se sitúe el investigador. La literatura en marketing y relaciones públicas se acerca más a la idea de que la identidad son los mecanismos de representación de lo que es la empresa, haciendo hincapié en los medios de representación simbólicos (logos e identidad visual preferentemente). Por su parte, la literatura en comportamiento organizacional se aproxima a la identidad corporativa desde la perspectiva de lo que en realidad es la organización, como el conjunto de rasgos y atributos que la caracterizan y le confieren especificidad, estabilidad y coherencia, en una tendencia a la antropomorfización de la organización, dotándola de rasgos esenciales como si se tratase de un organismo viviente. En esta área, los términos identidad corporativa e identidad organizacional han sido en ocasiones intercambiables, lo que no ha ayudado a su delimitación conceptual (Balmer, 2008). 
Identidad e imagen corporativas:

revisión conceptual e interrelación

Sin duda, esta diferencia de interpretaciones da lugar a la ambigüedad generada alrededor del concepto de identidad corporativa. Christensen y Askegaard, (200I) basan su conceptualización de identidad e imagen corporativas en el proceso de significación (o semiosis) de Peirce (1985), en el que intervienen: el objeto o referente, el signo o símbolo y el interpretante.

El signo o símbolo es cualquier cosa perceptible (palabra, síntoma, señal, letra, frase, etc.) que representa a algo, a su objeto o referente (Peirce, 1985). Ahora bien, ese signo o símbolo crea otro signo en la mente del individuo que lo interpreta: el interpretante, que se corresponde con el pensamiento subjetivo que interpreta a un significado. El proceso de significación de Peirce (1985) difiere del tradicional modelo lingüístico significante/significado, aportado por la escuela estructuralista de Saussure (1964 [1916]), incluyendo un tercer elemento, el interpretante, que deja espacio a la interpretación individual del significado. Para Peirce (1985), la relación entre un signo y un objeto tiene un sentido preciso para un individuo, vinculándose a afectos, recuerdos y experiencias, gracias al elemento interpretante. En el ámbito de la organización, el interpretante se correspondería con la noción de imagen corporativa (Christensen y Askegaard, 200I).

En el contexto organizacional, el signo puede ser un gesto, un logotipo, un anuncio, un eslogan, un producto, un texto escrito, etc. Para Christensen y Askegaard (200I: 304), el signo es la identidad corporativa, es decir, "la suma de señales que ayudan a sus diferentes audiencias a interpretar la organización". Estas señales pueden ser controlables (comunicación corporativa), suponiendo el perfil formal de la organización (cómo desearía ser interpretada), y no controlables, incluyendo elementos no planificados como las conductas negativas o los rumores (Christensen y Askegaard, 200I; van Riel y Balmer, 1997).

Según Christensen y Askegaard, (200I: 305), el signo o símbolo hace referencia a un objeto que es "la organización, su personalidad tal y como realmente es". Para estos autores, uno de los mayores problemas con los que se encuentra la investigación en identidad e imagen corporativas, sobre todo en el área de marketing, es la tendencia a considerar la identidad y la imagen como realidades objetivas, casi como realidades naturales, existentes con independencia del sujeto, y no como construcciones sociales (significados) que basan su existencia en las capacidades interpretativas de sus audiencias.

Asimismo señalan que no hay ninguna dimensión de la empresa más profunda, fundamental o más verdadera y objetiva, ya que también son construcciones 
simbólicas (y por lo tanto subjetivas), de igual naturaleza que las representaciones de la identidad e imagen de la organización. Así, los autores conciben la identidad y la imagen corporativa como "simulaciones histórico-sociales de realidades organizacionales" (Christensen y Askegaard, 200 I: 294), simulaciones cuya bondad o cualidad no se puede medir con base en su grado de congruencia con la realidad, sino en su poder retórico respecto a sus audiencias. Esta conceptualización de las nociones de identidad e imagen, como construcciones sociales formadas por la interacción con los otros, ha sido utilizada en los estudios provenientes del área de comportamiento organizacional (por ejemplo, en investigaciones sobre identidad organizacional en Albert y Whetten, 1985; Mael y Ashforth, 1992; y Dutton y Dukerich, I99I; así como en trabajos sobre las relaciones cultura-identidad-imagen en Hatch y Schultz, 1997 y 2002.

Entonces, el gran equívoco que rodea al término identidad corporativa supone, para Christensen y Askegaard (200I), que se le considere también como referente u objeto, como ethos de la empresa, como lo que objetivamente es la organización, además de ser el signo o símbolo en el proceso de significación de Peirce (1985). En la figura I se representa esta ambigüedad según el modelo de significación de Peirce.

INTERPRETANTE Imagen corporativa

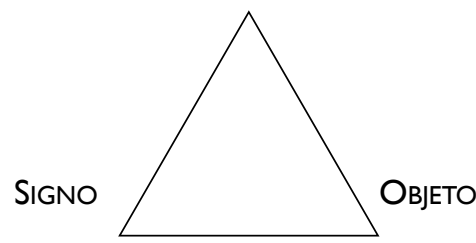

Identidad corporativa
Personalidad corporativa Identidad organizacional
INTERPRETANTE Imagen corporativa

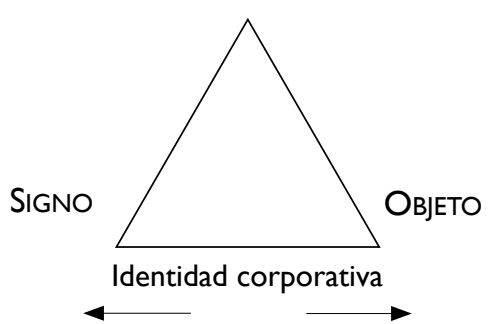

Fuente: Elaboración propia con base en Christensen y Askegaard (200I).

FIGURA I.AMBIGÜEDAD EN TORNO AL CONCEPTO DE IDENTIDAD CORPORATIVA:

“IDENTIDAD-OBJETO" E "IDENTIDAD-SIGNO” 
Identidad e imagen corporativas:

revisión conceptual e interrelación

Identidad-objeto: una noción

sobre lo que "es" la organización

Una de las mayores preocupaciones que ha originado la distinción entre identidad-objeto e identidad-signo es la idea de que, en ocasiones, las identidades e imágenes de una organización son falsas representaciones de su realidad (Alvesson, 1990; Christensen y Askegaard, 200I). Con la intención de hallar formas de conocer ese gap entre percepciones y realidad, la literatura ha generado nociones que dan a entender una concepción más profunda, fundamental y esencial de la organización (Markwick y Fill, 1997; Rodríguez del Bosque, 1995; Stuart, 1998 y 1999; Suvatjis y de Chernatony, 2004; van Riel, 1995). Se han empleado diversos términos para denominar esta noción más profunda o esencial (de hecho, uno de ellos ha sido el de identidad corporativa): personalidad corporativa (Abratt, 1989; Bernstein, 1984; Rodríguez del Bosque, 1995), carácter de la organización (Sen y Bhattacharya, 200I) e identidad organizacional (Albert y Whetten, 1985; Mael y Ashforth, 1992).

Abratt (1989), que considera la identidad corporativa como un mecanismo de expresión, introduce en su modelo de gestión de la imagen corporativa el concepto de personalidad corporativa (Bernstein, 1984). Abratt entiende la personalidad corporativa como el conjunto de elementos esenciales que confieren individualidad a la organización (valores corporativos, cultura corporativa, filosofía corporativa, estrategia y misión) y en los que se arraiga y se basa la identidad corporativa.

El concepto de identidad organizacional ha sido definido como aquello que los miembros perciben como los aspectos centrales, distintivos y duraderos en el carácter de una organización (Albert y Whetten, 1985); definición que ha sido utilizada por una gran cantidad de autores (Ahearne, Bhattacharya y Gruen, 2005; Bhattacharya, Rao y Glynn, 1995; Dutton y Dukerich, I99I; Dutton, Dukerich y Harquail, 1994; Mael y Ashforth, 1992). Todos ellos conciben la identidad organizacional como aquello que los miembros formales de la organización piensan y sienten respecto a ella, y que se deriva de su percepción individual de los atributos centrales, distintivos y duraderos que la caracterizan. Así, en el concepto de identidad se introduce un sujeto (el miembro formal de la organización), que es quien construye tal identidad a través de su percepción de los elementos esenciales de la organización.

Albert y Whetten (1985) clarifican que la identidad es una construcción social producida tras un proceso reflexivo de comparaciones intersubjetivas o 
interorganizacionales. Para estos autores, los miembros formales de la organización son quienes construyen esa identidad, mediante una especie de autopercepción o autoimagen de lo que es la organización, también denominada imagen interna (Moingeon y Ramanantsoa, 1997). Esto supone un enfoque demasiado endógeno de la identidad organizacional, como algo que se construye e interpreta dentro de la organización, aunque luego se proyecte al exterior y genere imágenes en las audiencias. Sin embargo, autores como Dutton y Dukerich (1991), Hatch y Schultz (1997) o Christensen y Askegaard (200I) han planteado cómo la construcción de la identidad organizacional tiene influencias externas o, expresado de otro modo, cómo la imagen influye en la propia identidad.

\section{Identidad-signo: mecanismos de expresión}

de la identidad corporativa

Un punto clave a la hora de analizar la identidad corporativa, entendida como el medio de expresión de lo que es la empresa, lo constituye conocer qué diferentes vías o mecanismos emplea la organización para tal expresión o, dicho de otra manera, qué integra la identidad corporativa. La literatura ha denominado mix de identidad corporativa al conjunto de mecanismos de expresión de identidad del que se vale la organización y que conforma su identidad corporativa (Birkigt y Stadler, 1986; Balmer, 200 I; Leuthesser y Kholi, 1997; Markwick y Fill, 1997; Melewar y Jenkins, 2002; van Riel, 1995).

El mix de identidad corporativa propuesto por Birkigt y Stadler (1986) consiste en cuatro elementos: la personalidad, el comportamiento, la comunicación y el simbolismo. En realidad, tal y como son descritos, para estos autores los mecanismos de expresión de identidad son los tres últimos elementos, en los cuales se cristaliza la personalidad de la organización; como se comprueba, se trata de un caso que ilustra la ambigüedad en torno a la noción de identidad corporativa. Van Riel (1995) tiene en cuenta esta consideración y depura el mix de identidad corporativa de Birkigt y Stadler (1986), dotándolo de un contenido coherente. En efecto, van Riel (1995) cree que la autorrepresentación de una organización se puede desarrollar a través de tres formas diferenciadas: el comportamiento, la comunicación y el simbolismo, que constituirían el mix de identidad corporativa. Para él, cualquier acción o expresión de una empresa se puede clasificar en alguno o en varios de estos tres elementos.

El comportamiento sería el medio de expresión de identidad más importante, ya que, en última instancia, los públicos objetivo evaluarán a la empresa por sus 
Identidad e imagen corporativas:

revisión conceptual e interrelación

acciones. Empero, según van Riel (1995), es posible matizar, filtrar, suavizar o enfatizar algunos aspectos del comportamiento gracias a los otros dos componentes del mix de identidad corporativa: la comunicación y el simbolismo.

La comunicación es entendida, en un sentido estricto o reducido, como la emisión de señales verbales o no verbales a las audiencias, sean internas o externas (Birkigt y Stadler, 1986; van Riel, 1995). La comunicación es el instrumento más flexible y el que se puede utilizar tácticamente con mayor rapidez, al permitir el envío directo de señales al público objetivo deseado. Aunque la organización genera procesos de comunicación formales y controlables, también se dan en ella comunicaciones informales y no controlables que hay que testear, ya que de igual forma son transmisoras de identidad (Christensen y Askegaard, 200I; van Riel y Balmer, 1997). La comunicación es quizá el instrumento más empleado como trasmisor de identidad, de ahí la importancia que en los últimos años ha adquirido generar procesos de comunicación coordinados y coherentes respecto a lo que es, hace o pretende la organización. La comunicación corporativa y la comunicación de marketing integrada se han convertido en herramientas de gestión básicas, posibilitadoras de ventajas competitivas (Balmer, 2008; van Riel, 1995).

Por último, el simbolismo (íntimamente relacionado con la identidad visual de la organización) armoniza y aglutina las otras expresiones de identidad corporativa, ofreciendo al público una indicación implícita de lo que representa o desea representar la empresa (Chajet y Shachtman, 1998; van Riel, 1995).

\section{Conceptualizaciones en torno al término imagen}

El término imagen ha sido muy estudiado en la literatura, $y$, aunque también ha sido objeto de cierta ambigüedad, las nociones aparecidas en torno suyo se han definido o depurado más que en el caso del de identidad. Respecto a la imagen han aparecido en la literatura diversos conceptos, distintos pero interrelacionados, como imagen corporativa o de marca (Abratt, 1989; Balmer, 200I; Bernstein, 1984; Riordan, Gatewood y Barnes Bill, 1997; Spector, I 96I; van Riel, 1995), imagen organizacional (Alvesson, 1990; Dutton y Dukerich, 1991) o, más recientemente, asociaciones corporativas (Ahearne, Bhattacharya y Gruen, 2005; Berens y van Riel, 2004; Brown y Dacin, 1997; Sen y Bhattacharya, 200 I). En el cuadro 2 se muestran varias conceptualizaciones sobre el término imagen encontradas en la literatura. 
CuAdRO 2. CONCEPTUALIZACIONES EN TORNO AL TÉRMINO IMAGEN

Autor(es) Definición

\section{Concepto de imagen}

Martineau Imagen es la suma de las cualidades funcionales y atributos

Costa

Topalian psicológicos que existen en la mente del consumidor.

Bernstein (1984) Imagen de la empresa es la resultante de múltiples y diversos mensajes que, acumulados en la memoria colectiva, configuran una globalidad significativa capaz de influir en los comportamientos y determinarlos.

Imagen es el perfil del objeto, es decir, la suma de impresiones y expectativas reunidas en la memoria del individuo.

Imagen es el modo en que los stakeholders perciben los indicadores de identidad de una organización. Se forma a través de encuentros con las características de la organización, y es el resultado neto de la interacción de todas las experiencias, creencias, sentimientos, conocimientos e impresiones que cada stakeholder posee sobre la organización.

Barich y Kotler Imagen es la suma de creencias, actitudes e impresiones que una (I99I) persona o grupo guardan de un objeto.

\section{Concepto de imagen corporativa}

Spector (196I)

Abratt (1989)

Riordan, Gatewood y Barnes Bill (1997) Ind (1997)
Imagen corporativa es la suma total de las percepciones de las características de una empresa que posee un individuo.

Imagen corporativa no es lo que la empresa cree ser, sino los sentimientos y creencias sobre la compañía que existen en la mente de sus audiencias.

Imagen corporativa es la percepción individual de las acciones actividades y compromisos de una organización.

Imagen corporativa es el dibujo mental que una audiencia tiene sobre una organización, generado a través de la acumulación de todos los mensajes recibidos. 
Identidad e imagen corporativas:

revisión conceptual e interrelación

CUADRO 2. CONCEPTUALIZACIONES EN TORNO AL TÉRMINO IMAGEN

Inthen 22

\begin{tabular}{|c|c|}
\hline Autor(es) & Definición \\
\hline $\begin{array}{l}\text { Villafañe } \\
\text { (1998) }\end{array}$ & $\begin{array}{l}\text { La imagen corporativa es el resultado de la integración, en la } \\
\text { mente de los públicos con los que la empresa se relaciona, de un } \\
\text { conjunto de imágenes que, con mayor o menor protagonismo, la } \\
\text { empresa proyecta hacia el exterior. }\end{array}$ \\
\hline $\begin{array}{l}\text { Christensen } \\
\text { y Askegaard } \\
(2001)\end{array}$ & $\begin{array}{l}\text { La imagen corporativa es la impresión creada o estimulada a } \\
\text { de la identidad corporativa. }\end{array}$ \\
\hline $\begin{array}{l}\text { Balmer } \\
(2001)\end{array}$ & $\begin{array}{l}\text { La percepción mental que de una organización posee un individuo } \\
\text { o grupo de individuos. }\end{array}$ \\
\hline $\begin{array}{l}\text { Christie } \\
(2002)\end{array}$ & $\begin{array}{l}\text { Imagen corporativa es un término holístico que incluye tres } \\
\text { perspectivas interrelacionadas: la autoimagen, la imagen } \\
\text { proyectada y la imagen percibida de la organización. }\end{array}$ \\
\hline
\end{tabular}

\section{Concepto de imagen organizacional}

Alvesson La imagen organizacional es (I) una impresión holística que tiene (1990) un individuo o un grupo particular hacia una organización y (2) la comunicación por parte de la organización de un dibujo proyectado y fabricado por ella misma.

Dutton y Imagen organizacional es el modo en el que los Dukerich miembros de la organización creen que otros ven su (I99I) organización.

\section{Concepto de asociaciones corporativas}

Brown Asociaciones corporativas es una denominación genérica y Dacin de toda la información que sobre una compañía (1997) posee una persona.

De la revisión de las definiciones del cuadro 2 se desprende que hay consenso entre todos los autores en asociar el término imagen con el de percepción (Bernstein, 1984; Balmer, 2001; Christie, 2002; Riordan, 1997; Spector, 196I), o de relacionarlo con el resultado de una impresión (Alvesson, 1990; Barich y Kotler, I99I; Bernstein, 1984; Christensen y Askegaard, 200 I;Dowling, 1986). Así, según estas conceptualizaciones: la imagen tendría una naturaleza acumulativa o aditiva, ya que se configura como la suma (Barich y Kotler, 1991; 
Martineau, 1958; Spector, I96I; Topalian, 1984), el resultado (Villafañe, 1998), la acumulación (Ind, 1997), el conjunto (Dowling, 1986) o la impresión holística (Alvesson, 1990) de creencias, actitudes, experiencias, sentimientos, impresiones o informaciones, que un sujeto -el consumidor (Martineau, 1958), los stakeholders (Bernstein, 1984), los individuos en general (Balmer, 200 I; Brown y Dacin, 1997; Spector, 196I) - posee de un objeto, que es la fuente de la que proviene la imagen. Existen varios niveles de imagen -producto, marca, empresa, sector- (Barich y Kotler, 1991).

En la literatura sobre marketing y teoría organizacional aparecen varias acepciones de imagen entrelazadas, destaca la de imagen corporativa. Este término se refiere a la imagen cuyo objeto es la organización misma, y cuyo sujeto (quien la percibe) se encuentra en el exterior de la empresa (audiencias, públicos, stakeholders externos) (Balmer, 2008). Desde esta perspectiva, la noción de imagen corporativa aparece como sinónimo de identidad percibida: la identidad corporativa proyecta la personalidad de la organización y provoca imágenes en sus públicos externos (Balmer, 200I; Markwick y Fill, 1997).

De forma análoga a la imagen corporativa se encuentra el constructo de imagen de marca, aunque esté referido al objeto-marca y no al objeto-organización, difíciles de separar perceptualmente cuando nos referimos a una marca corporativa (Balmer y Gray, 2003; Hatch y Schultz, 2003). La imagen de marca alude al conjunto de "percepciones sobre la marca que se reflejan como asociaciones existentes en la memoria del consumidor" (Keller, 1993: 3). Entre estas asociaciones, Aaker (1997) subraya el conjunto de características humanas asociadas a las marcas (personalidad de marca), concentradas en torno a cinco dimensiones: sinceridad, emoción, competencia, sofisticación y aspereza. Por último, un concepto muy utilizado en marketing y estrechamente ligado al de imagen corporativa o imagen de marca es el de posicionamiento. El posicionamiento perceptual de una marca o una corporación (la posición que ocupa en la mente de los públicos) se configura por una serie de atributos característicos que los consumidores asocian a aquélla en relación con la competencia (Aaker, 199I). De este modo, el concepto de imagen corporativa y el de posicionamiento se encuentran íntimamente vinculados, con la particularidad de que este último implica un marco de referencia constituido por la competencia.

Rodríguez del Bosque (1995) establece que existen tres posibles estructuras de relación entre la imagen corporativa y la imagen de marca, estructuras que se sitúan en un continuo: I) la estructura monolítica, aquella en la que 
Identidad e imagen corporativas:

revisión conceptual e interrelación

"una única identidad se mantiene conjuntamente para la empresa y su producto o productos" (Rodríguez del Bosque, 1995: 86); 2) la estructura endosada, en la cual la imagen corporativa es utilizada como respaldo o apoyo del nombre del producto, produciéndose un efecto paraguas que da valor a la imagen de la marca; y 3 ) la estructura simple, en la que la imagen de la marca del producto es independiente de la imagen de la empresa.

Según la literatura, la concepción de imagen corporativa como identidad percibida supone dos consideraciones importantes a tener en cuenta: I) que la empresa no tiene sólo una imagen, sino tantas como individuos interactúan con ella (Barich y Kotler, I99I; Dowling, 1986; Markwick y Fill, I997; Riordan, Gatewood y Barnes Bill, 1997); y 2) que la imagen es la suma de todo un conjunto de imágenes unitarias o específicas de la empresa o la marca (Brown y Dacin, 1997; Spector, I96I; van Riel, 1995).

Como se ha visto, el proceso de significación de Peirce (1985) permite explicar que la imagen corporativa se construye en un proceso social y subjetivo. Según Christensen y Askegaard (200l: 305), el tercer elemento que interviene en el proceso de significación, el interpretante, se corresponde con la imagen corporativa:"una impresión creada o estimulada por la señal que es la identidad corporativa" y que se refiere a un objeto, la personalidad corporativa.

La segunda consideración hace referencia a que la imagen de un objeto (organización, marca) se configura como una especie de mosaico donde se insertan coherentemente todas las percepciones e información de ese objeto que recibe un sujeto (Keller, 1993;Villafañe, 1998). En efecto,"la formación de la imagen de un objeto se realiza por medio de cadenas o redes de asociaciones que se construyen durante un periodo de tiempo como consecuencia del impacto de estímulos", que se van almacenando en la memoria del individuo (van Riel, 1995: 79). El conjunto y ordenamiento coherente de tales asociaciones (imágenes unitarias) genera una impresión global del objeto (en el caso de las organizaciones, imagen corporativa). Se trataría de una concepción gestáltica de la imagen, en la que ésta es el resultado de un proceso integrador realizado en la mente de los sujetos (Villafañe, 1998; Costa, 1977).

En este sentido, es apreciable la introducción en el área de marketing del término asociaciones corporativas, derivada de la investigación en psicología sobre modelos de redes asociativas de la memoria, aludiendo a las creencias, sentimientos y actitudes basados en la memoria que un individuo tiene respecto a una organización concreta (Brown y Dacin, 1997; Sen y Bhattacharya, 200 I; Berens y van Riel, 2004; Berens, van Riel y van Rekom, 2007). 


\section{La naturaleza interdependiente de la identidad y la imagen: el papel de la cultura}

Una vez revisados los conceptos de identidad e imagen, es necesario estudiar qué relación se establece entre ambos. En este apartado se aborda la naturaleza interdependiente de esa relación gracias al papel desempeñado por la cultura organizacional.

La relación tradicional que se ha establecido entre identidad e imagen, sobre todo en los estudios del tema provenientes del área de marketing, se ha basado en el modelo comunicativo clásico emisor-receptor, donde la imagen depende de la identidad (Christensen y Askegaard, 200 I; Dowling, 1986; Margulies, 1977). Esta relación ha estado en constante revisión, lo cual se evidencia por la intuición, expresada por no pocos autores (Abratt, 1989; Dutton, Dukerich y Harquail, 1994; Stuart, 1999), de que el modo en que es percibida la organización (imagen) también influye en cómo es ésta y cómo se proyecta a sus públicos (identidad).

Desde el área de estudio del comportamiento organizacional se ha dado un mayor consenso respecto a esta interdependencia entre identidad e imagen, como consecuencia de la idea de que éstos son constructos relacionales formados por la interacción con los otros (Albert yWhetten, 1985; Mael yAshforth, 1992). Albert y Whetten (1985) creen que la identidad organizacional se configura como resultado de un proceso de comparaciones y reflejos interorganizacionales realizados por los miembros de la empresa y ordenados a lo largo del tiempo. Citando el trabajo de Erikson (1968) desde el campo de la psicología, Albert y Whetten (1985: 273) describen el proceso de formación de la identidad organizacional como paralelo al producido con la identidad individual: "la identidad del individuo se forma en términos de una serie de comparaciones interpersonales: (I) los otros comparan al individuo consigo mismos; (2) la información referente a esa evaluación es transmitida al individuo a través de conversaciones entre las partes y éste toma en cuenta ese feedback para hacer sus comparaciones personales con el resto, lo que; (3) afecta cómo se definen a sí mismos". Definitivamente, del mismo modo en que la identidad influye en cómo es percibido el sujeto (imagen), la formación de la identidad es un proceso dialógico en el que el individuo toma en consideración cómo lo perciben los otros.

Sin duda, entre las aportaciones más valiosas que ayudan a explicar la relación identidad-imagen están las efectuadas por Hatch y Schultz (1997 y 
Identidad e imagen corporativas:

revisión conceptual e interrelación

2002) en sus trabajos sobre el papel desempeñado por la cultura organizacional en esa relación. Un hecho trascendental para estos autores es que hoy en día las fronteras que separan el ámbito interno y externo en una organización son demasiado estrechas y están profundamente interrelacionadas como para realizar una distinción clara entre éstos. Así, mientras la distinción internoexterno se colapsa en la organización (Christensen y Askegaard, 200I), ésta se encuentra más abierta a influencias externas, y la identidad está cada vez más influenciada por la imagen de la empresa.

Hatch y Schultz (1997) fundamentan la interdependencia de la relación identidad e imagen en la función de amalgama que cumple la cultura organizacional. Ésta es definida como el "contexto simbólico en el que son formadas las interpretaciones de la identidad de la organización y son formuladas las intenciones de influencia en la imagen de la empresa" (Hatch y Schultz, 1997: 360). De acuerdo con estos autores, la identidad de la organización, que es proyectada desde parámetros culturales, provee del material simbólico necesario para que se produzca la construcción y comunicación de la imagen corporativa por parte de otros públicos; a continuación, "estas imágenes comunicadas son reabsorbidas al sistema cultural de la organización cuando son utilizadas como artefactos culturales de proyección de identidad: así, quiénes somos se refleja en lo que hacemos y en cómo otros interpretan lo que somos y lo que hacemos" (Hatch y Schultz, 1997: 36I).

En consecuencia, la cultura es el contexto donde se mantiene y desarrolla la identidad, y donde se conforma la imagen, ya que ésta es representada e interpretada con base en los presupuestos culturales y valores que tiene la organización y los públicos que la rodean. Dicho de otro modo, las maneras en que la empresa se representa y proyecta a sí misma (identidad) y en que los diferentes públicos (internos o externos) perciben dichas representaciones (imagen) están irremediablemente arraigadas y justificadas por la cultura que rodea a la organización y a los públicos que con ella interactúan (Hatch y Schultz, 1997).

Hatch y Schultz (2002) proponen un modelo que vincula de manera simultánea la identidad, la imagen y la cultura de la organización, en una relación triangular e interdependiente que recuerda a la asimilación realizada por Christensen y Askegaard (200I) del proceso de significación de Peirce (1985) en la organización: cultura como objeto o referente, identidad como signo, e imagen como interpretante. Hatch y Schultz (2002) articulan los tres conceptos mediante dos sendas de relación con dos procesos independientes cada 
una (véase figura 2): I) primera senda de relación, con flechas en blanco: el proceso de reflejo de las imágenes de los públicos externos en la identidad y el proceso de reflexión sobre la pregunta "iquiénes somos?", describe la influencia de las imágenes externas en la cultura de la organización; 2), segunda senda de relación, con flechas oscuras: el proceso de expresión de la cultura a través de la identidad y el proceso de impresión de imágenes en los otros producido por dicha identidad, describe la influencia de la cultura en las imágenes que los otros poseen de la organización.

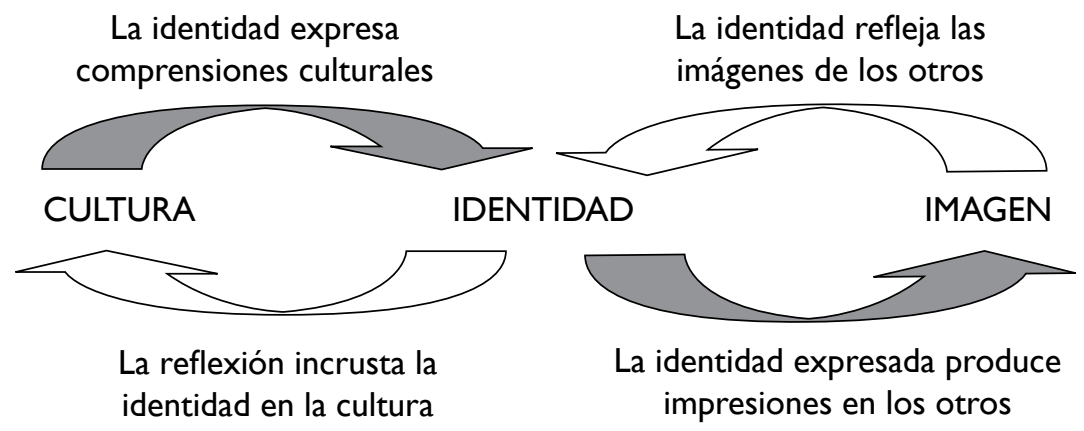

Fuente: Hatch y Schultz (2002).

FIGURA 2. DINÁMICAS ENTRE IDENTIDAD, IMAGEN Y CULTURA

La bibliografía ha demostrado cómo la organización tiene en cuenta para la construcción de su identidad lo que los públicos perciben de ella, es decir, la imagen corporativa (Dutton y Dukerich, 199I; Dutton, Dukerich y Harquail, 1994). Para Dutton y Dukerich (199I), la existencia de una discrepancia entre lo que los miembros de la organización piensan de ella (identidad organizacional) y lo que creen que los demás piensan de la organización (imagen corporativa) es el desencadenante del proceso de reflejo (Hatch y Schultz, 2002), por el que la identidad se modifica asumiendo las imágenes externas que de ella se tienen.

De tal modo, se desprende que, para Dutton y Dukerich (I99I), el proceso de reflejo viene absolutamente mediado por las percepciones de los miembros de la organización, quienes no sólo consideran las imágenes externas para desarrollar su identidad (proceso de reflejo), sino que también se basan en lo que perciben de sí mismos (imagen interna). Cuando la identidad refleja 
Identidad e imagen corporativas:

revisión conceptual e interrelación

la imagen de los otros comienza un proceso reflexivo (y por lo tanto consciente) en el que los individuos tratan de pensarse, comprenderse y explicarse a sí mismos como organización (Hatch y Schultz, 2002). Tanto el proceso de reflejo como el proceso reflexivo sólo se pueden desarrollar en el contexto producido por la cultura, de manera que cuando los miembros de la organización reflexionan sobre su identidad lo hacen necesariamente con referencia a su cultura organizacional, quedando así incrustadas sus reflexiones en las comprensiones culturales de la organización. Entonces, las imágenes de los públicos externos quedan fijadas en la cultura de la organización, tras haber sido reflejadas por la identidad y haber reflexionado sobre ellas desde parámetros culturales.

El mecanismo por el que la cultura influye a la imagen de los públicos es más intuitivo. En primer lugar, la identidad se utiliza como mecanismo de expresión de la cultura (Hatch y Schultz, 2002). La comunicación de la identidad permite a los miembros de la organización (re)presentarse como tales no sólo ante ellos sino, lo que es más importante, ante los demás. Entonces, los valores, creencias, asunciones básicas de la organización, que forman parte de su cultura, se manifiestan a través de la identidad. Por último, la identidad expresada provoca impresiones (imagen corporativa, asociaciones corporativas) en la mente de los públicos o audiencias externas (Dutton y Dukerich, 1991; Hatch y Schultz, 2002).

\section{Conclusiones, implicaciones y líneas de investigación futura}

Esta investigación se planteó con dos objetivos secuenciales. En primer lugar, realizar una revisión de la bibliografía que trata las nociones de identidad e imagen corporativa, para ayudar a su clarificación conceptual. En segundo lugar, analizar la naturaleza interdependiente de identidad e imagen corporativas gracias al papel integrador ejercido por la cultura organizacional.

La revisión bibliográfica en torno al concepto de identidad corporativa hace explícita la ambigüedad con la que ha sido tratado el constructo. Por un lado, un conjunto de trabajos considera que el concepto de identidad corporativa encierra una noción profunda y esencial de lo que es la organización, de su ethos, de aquello que la caracteriza y le confiere singularidad (Balmer, 200 I; Balmer y Soenen, 1999; Hawn, 1998; Reitter y Ramanantsoa, 1985; van Rekom, 1997; van Riel y Balmer, 1997). Por otro, hay autores que juzgan que la noción de identidad corporativa se ciñe exclusivamente a los modos o mecanismos de 
expresión (comportamiento, comunicación, simbolismo) de los que dispone la organización para proyectar su esencialidad, su personalidad corporativa (Abratt, 1989; Christensen y Askegaard, 200 I; Leuthesser y Kholi, 1997; Stuart, 1999; van Riel, 1995). Atendiendo a la terminología del proceso de significación de Peirce (1985), la primera corriente entiende que la identidad corporativa es a la vez objeto y signo del proceso; la segunda cree que la identidad corporativa es el signo de la personalidad corporativa, el objeto (Christensen y Askegaard, 200I).

Por su parte, la revisión conceptual en torno a la noción de imagen denota un mayor consenso en asociar este término con el de percepción. La imagen se configuraría, entonces, como el resultado global de la suma de creencias, experiencias, sentimientos o información (Barich y Kotler, 199I; Martineau, 1958; Spector, 196I; Topalian, 1984) que un consumidor u otros stakeholders (Balmer, 200 I; Brown y Dacin, 1997; Spector, 196I) poseen de una organización o marca (Barich y Kotler, | 991). Alrededor de esta noción general de imagen aparecen conceptos relacionados, tales como la imagen corporativa, imagen de marca, asociaciones corporativas o posicionamiento, que conviene distinguir adecuadamente en aras de una mejor gestión de los mismos.

La indagación bibliográfica permite concluir que identidad e imagen corporativas están interrelacionadas: las impresiones y percepciones de los públicos (imagen) se construyen sobre la comunicación de la organización (identidad); además, la imagen corporativa, en cierto modo, construye la organización en sí misma, por su propia lectura de esas impresiones externas (Christensen y Askegaard, 200I). Este proceso diálogico identidad-imagen es posible gracias a la función de amalgama que cumple la cultura organizacional.

En nuestra opinión, este esfuerzo de clarificación y ordenación conceptual de las nociones de identidad e imagen corporativas tiene una potencial aplicabilidad en la gestión empresarial. Mediante este trabajo, quienes deseen gestionar de mejor modo su propia identidad e imagen corporativas disponen de una ordenación lógica de estas variables organizacionales, de las ambigüedades con que pueden ser abordadas, y de su interrelación. Esta revisión teórica puede servir de guía para quienes deseen desarrollar programas de gestión de la identidad y mejora de la imagen corporativa.

Por último, este trabajo conceptual abre algunas oportunidades de investigación, sobre todo con un enfoque empírico. Por ejemplo, en la literatura han aparecido varios modelos teóricos de gestión de la identidad o formación de imagen corporativa (Abratt, 1989; Balmer y Gray, 1999;Dowling, 1986; Markwick 
Identidad e imagen corporativas:

revisión conceptual e interrelación

y Fill, 1997; Stuart, 1999; van Riel y Balmer, 1997); se hace necesario un esfuerzo por estimar empíricamente dichos modelos, en diversos contextos culturales y competitivos, de manera que se puedan generalizar los supuestos que subyacen a la relación interdependiente de identidad e imagen corporativas.

Para ello, sería interesante profundizar en los modos de poner en operación la medición de la identidad e imagen corporativas; pues, por la propia complejidad de su naturaleza, éstos son constructos de carácter multidimensional difíciles de capturar (Melewar y Karaosmanoglu, 2006; van Rekom, 1997; van Riel y Balmer, 1997). Por eso, convendría desarrollar modelos de medida que trataran de aproximar estas variables y que posibilitaran su inclusión en modelos más complejos relacionándolas con respuestas cognitivas, afectivas y de comportamiento de diversos stakeholders (trabajadores, consumidores o inversionistas, entre otros).

\section{FUENTES CONSULTADAS}

Aaker, D.A. (|99|). Gestión del valor de la marca. Madrid: Díaz de Santos. (2004). "Leveraging the Corporate Brand". California Management Review, 46 (3), 6-18.

Aaker,J.(1997)."Dimensions of Brand Personality”.Journal of Marketing Research, 34 (3), 347-356.

Abratt, R. (1989). "A New Approach to the Corporate Image Management Process". Journal of Marketing Management, 2 I (I), 63-73.

Ahearne, M., C. Bhattacharya y T. Gruen (2005). "Beyond the Brand: Antecedents and Consequences of Customer-Company Identification". Journal of Applied Psychology, 90 (3), 574-585.

Albert, S.y D.Whetten (1985). “Organizational Identity”. Research in Organizational Behavior, 7, 263-295.

Alessandri, S. (200I).“Modelling Corporate Identity:a Concept Explication and Theoretical Explanation". Corporate Communications: An International Journal, 6 (4), I73-I82.

Alvesson, M. (1990). "Organization: from Substance to Image”. Organization Studies, II, 373-394.

Balmer, J. (200I). "Corporate Identity, Corporate Branding and Corporate Marketing: Seeing through the Fog". European Journal of Marketing, 35 (3/4), 248-291. 
(2008). “Identity Based Views of the Corporation. Insights from Corporate Identity, Organisational Identity, Social Identity,Visual Identity, Corporate Brand Identity and Corporate Image". European Journal of Marketing, 42 (9/10), 879-906.

Balmer, J. y E. Gray (1999). "Corporate Identity and Corporate Communications: Creating a Competitive Advantage". Corporate Communications: An International Journal, 4 (4), I 7 I- I 76.

(2003).“Corporate Brands:What are they? What of them?" European Journal of Marketing, 37 (7/8), 972-997.

y G. Soenen (1999). "The Acid Test of Corporate Identity Management". Journal of Marketing Management, I5 (I/3), 69-92.

Barich, H.y P. Kotler ( 199 I). “A Framework for Marketing Image Management”. MIT Sloan Management Review, 32 (2), 94- 104.

Berens, G. y C. van Riel (2004). "Corporate Associations in the Academic Literature:Three Main Streams of thought in the Reputation Measurement Literature". Corporate Reputation Review, 7 (2), I6I-I 78.

C. van Riel y J. van Rekom (2007). "The CSR-quality trade-off: when can Corporate Social Responsibility and Corporate Ability compensate each other?" Journal of Business Ethics, 74, 233-252.

Bernstein, D. (1984). La imagen de la empresa y la realidad. Crítica de las comunicaciones corporativas. Barcelona: Plaza \& Janés.

Bhattacharya, C.y S.Sen (2003). “Consumer-company Identification:a Framework for Understanding Consumers' relationships with Companies”.Journal of Marketing, 67, 76-88.

H. Rao y M. Glynn (1995). "Understanding the Bond of Identification: an Investigation of its Correlates among Art Museum Members". Journal of Marketing, 59 (4), 46-57.

Birkigt, K. y M.M. Stadler (1986). Corporate Identity. Grundlangen, Funktionen, Fallspielen. Verlag Moderne Industrie, Landsberg and Lech.

Brown, T.y P. Dacin (1997). "The Company and the Product: Corporate Associations and Consumer Product Responses".Journal of Marketing, 6I, 68-84.

Chajet, C. y T. Shachtman (1998). Image by Design: from Corporate Vision to Business Reality. Nueva York: McGraw-Hill.

Christensen, L.y S.Askegaard (200I). "Corporate Identity and Corporate Image Revisited: a Semiotic Perspective". European Journal of Marketing, 35 (3/4), 292-3I5. 
Identidad e imagen corporativas:

revisión conceptual e interrelación

Christie, D. (2002). A Trilateral Model for the Management of Corporate Image: an Examination of the Inter-relationship between an Organization's self Image, its Projected Image and its Perceived Image. Tesis doctoral, School of Management, Faculty of Commerce and Management, Griffith University.

Cornelissen, J.y W. Elving (2003). “Managing Corporate Identity: an Integrative Framework of Dimensions and Determinants". Corporate Communications:An International Journal, 8 (2), I I4- I 20.

Costa,J. (1977). La imagen de la empresa. Métodos de comunicación integral. Biblioteca de la Comunicación del Centro de Investigación y Aplicaciones de la Comunicación (CIAC), Madrid: Ibérico-Europea de Ediciones.

Dowling, G.R. (1986). "Managing your Corporate Images". Industrial Marketing Management, 15, 109-15.

Dutton, J. y J. Dukerich (199I). "Keeping an Eye on the Mirror: Image and Identity in Organizational Adaptation”. Academy of Management Journal, 34 (3), 5 I7-554.

J.Dukerich y C. Harquail (1994).“Organizational Images and Member Identification”. Administrative Science Quarterly, 39 (2), 239-263.

Erikson, E. (1968). Identidad, juventud y crisis. Buenos Aires: Paidós.

Gioia, D., M. Schultz y K. Corley (2000). "Organizational Identity, Image, and Adaptive Instability". The Academy of Management Review, 25 (I), 63-8I.

Gray, E. y J. Balmer (1998). “Managing Image and Corporate Reputation”. Long Range Planning, 3I (5), 685-692.

Hatch, M.y M. Schultz (1997)."Relations between Organizational Culture, Identity and Image". European Journal of Marketing, 3I (5/6), 356-365.

(2002). "The Dynamics of Organizational Identity". Human Relations, 55 (8), 989-1018.

(2003)."Bringing the Corporation into Corporate Branding”. European Journal of Marketing, 37 (7/8), I04I- 1064.

Hawn, R. (1998). “Image vs. Identity”. Trends, I4, 22-27.

Ind, N. (1997). The Corporate Brand. Londres: Macmillan.

Keller, K. (1993). “Conceptualizing, Measuring and Managing Customer Based Brand Equity". Journal of Marketing, 57, I-22.

Leuthesser, L.y C. Kholi ( 1997)." "Corporate Identity: the Role of Mission Statements”. Business Horizons, 40 (3), 59-66. 
Mael,A.y E.Ashforth (1992). "Alumni and their Alma Mater: a Partial Test of the Reformulated Model of Organizational Identification". Journal of Organizational Behavior, 13, 103-123.

Margulies, W.P. (1977). "Make the most of your Corporate Identity”. Harvard Business Review, julio-agosto, 66-72.

Markwick, N. y C. Fill (1997). "Towards a Framework for Managing Corporate Identity". European Journal of Marketing, 3I (5/6), 396-409.

Martineau, P. (1958). "The Personality of the Retail Store”. Harvard Business Review, 36, 47-55.

Melewar, T. y E. Jenkins (2002). “Defining the Corporate Identity Construct”. Corporate Reputation Review, 5 (I), 76-93.

y E. Karaosmanoglu (2006). "Seven Dimensions of Corporate Identity. A Categorisation from the Practitioners' Perspectives”. European Journal of Marketing, 40 (7/8), 846-869.

Moingeon, B.y B. Ramanantsoa (1997)." "Understanding Corporate Identity: the French School of Thought". European Journal of Marketing, 3I (5/6), 383-395.

Olins, W. (|99|). Identidad corporativa: proyección en el diseño de la estrategia comercial. Madrid: Celeste.

Otubanjo, B. y T. Melewar (2007). “Understanding the Meaning of Corporate Identity: a Conceptual and Semiological Approach". Corporate Communications: An International Journal, I2 (4), 4I4-432.

Peirce, C. (1985). “Logic as Semiotic; the Theory of Signs”, en R. Innis. Semiotics. An Introductory Anthology. Bloomington: Indiana University Press, 4-23 [1897-1910].

Poiesz,T.B.C. (1988).“The Image Concept: Its Place in Consumer Psychology and Its Potential for Other Psychological Areas". Ponencia presentada en el XXIVth International Congress of Psychology, Sidney, Australia.

Reitter, R. y B. Ramanantsoa (1985). Povoir et politique. Au dèla de la cultuire d'entreprise. París: McGraw-Hill.

Riordan, C.M., R.D. Gatewood y J. Barnes Bill (1997). “Corporate Image: Employee Reactions and Implications for Managing Corporate Social Performance". Journal of Business Ethics, 16, 40I-4I 2 .

Rodríguez del Bosque, I. (I995). “La comunicación de la imagen de la empresa”. Alta Dirección, 30 (I8I), 79-9I.

Saussure, F. (1964). Curso de lingüística general. Buenos Aires: Losada [1916]. 
Identidad e imagen corporativas:

revisión conceptual e interrelación

Sen, S. y C. Bhattacharya (200I). "Does Doing Good always Lead to Doing Better? Consumer Reactions to Corporate Social Responsibility". Journal of Marketing Research, 38 (2), 225-243.

Spector,A. (1961)."Basic Dimensions of the Corporate Image".Journal of Marketing, 25 (6), 47-5I.

Stuart, H. (1998).“"Exploring the Corporate Identity/Corporate Image Interface: an Empirical Study of Accounting Firms". Journal of Communications Management, 2 (4), 357-37I.

(1999)."Towards a Definitive Model of the Corporate Identity Management Process". Corporate Communications:An International Journal, 4 (4), 200-207.

Suvatjis, J.y L. de Chernatony (2004). Corporate identity modelling: a review and presentation of the six station model for corporate identity. Birmingham: Centre for Research in Brand Marketing, Birmingham Business School, University of Birmingham (Working paper).

Topalian, A. (1984). "Corporate Identity: Beyond the Visual Overstatements". International Journal of Advertising, 3 (I), 55-62.

Van Rekom,J. (1997). “Deriving an Operational Measure of Corporate Identity”. European Journal of Marketing, 3 I (5/6), 4I 0-422.

Van Riel, C. (1995). Comunicación corporativa. Madrid: Prentice Hall. y J.Balmer (1997)."Corporate Identity: the Concept, its Measurement and Management". European Journal of Marketing, 3I (5/6), 340-355.

Villafañe, J. (1998). Imagen positiva. Gestión estratégica de la imagen de las empresas. Madrid: Pirámide. 